\title{
MODEL BISNIS DAN ANTARMUKA PELANGGAN E-COMMERCE PADA PT. SMG
}

\author{
Rudy; Anita P.W.; Anita O.; Octaffany \\ Jurusan Sistem Informasi, Fakultas Ilmu Komputer, Binus University \\ Jl. K.H. Syahdan No.9, Palmerah, Jakarta Barat 11480 \\ rudy@binus.edu;
}

\begin{abstract}
PT. SMG is a company which sells music and movies product in CDs, VCDs and DVDs. PT. SMG relies its business on direct selling through its outlets. PT. SMG needs a solution to facilitate the customers' needs in getting product information and online transactions. E-commerce can be use to develop business and provide an alternative solution to customers on how to transact and obtain product information from PT. SMG using the internet. The objective of this study is to design a business model and customer interface of e-commerce website for PT. SMG. The methodology uses e-commerce business model and customer interface design by Rayport and Jaworski. The website interface design uses a 7C framework approach: Context, Content, Communication, Commerce, Connection, Community and Customization. The result achieved is an e-commerce website that helps sales system and enhances the company competitiveness. The conclusions obtained are that PT. SMG can take advantage of e-commerce to support their sales system and the business model online for PT. SMG is the widest-assortment model.
\end{abstract}

Keyword: e-commerce, website, business model, user interface.

\begin{abstract}
ABSTRAK
PT. SMG adalah perusahaan yang bergerak dibidang penjualan music dan film dalam bentuk $C D$, $V C D$ dan DVD. Bisnis PT. SMG masih bergantung pada penjualan langsung melalui gerai-gerainya. Untuk itu PT. SMG membutuhkan solusi untuk memudahkan pada pelanggannya mendapatkan informasi produk dan bertransaksi. E-commerce dapat dimanfaatkan untuk mengembangkan bisnis dan memberikan alternative lain kepada para pelanggan untuk bertransaksi dan mendapatkan informasi produk dengan memanfatkan internet. Tujuan penulisan adalah merancang model bisnis dan antarmuka pelanggan website e-commerce bagi PT. SMG. Metode yang digunakan adalah perancangan bisnis model dan antarmuka pelanggan e-commerce menurut Rayport dan Jaworski. Perancangan website menggunakan pendekatan 7C framework: Context, Content, Communication, Commerce, Connection, Community dan Customization. Hasil yang dicapai berupa website e-commerce yang membantu sistem penjualan pada PT. SMG dan meningkatkan daya saing PT. SMG. Simpulan yang didapat adalah PT. SMG dapat memanfaatkan e-commerce untuk mendukung sistem penjualannya dan model bisnis PT. SMG adalah widest-assortment model.
\end{abstract}

Kata kunci: e-commerce, website, model bisnis, antarmuka pelanggan 


\section{PENDAHULUAN}

Persaingan dalam dunia bisnis kian kompetitif, untuk itu perusahaan dituntut untuk dapat memanfaatkan peluang dan mengikuti perubahan agar dapat tetap bersaing dengan perusahaanperusahaan sejenis lainnya. Ketersediaan informasi yang aktual, produk yang beragam dan berkualitas, dan metode penjualan yang tepat merupakan beberapa faktor penting yang harus dipertimbangkan oleh perusahaan. Teknologi yang ada saat ini dan dapat membantu perusahaan dalam meningkatkan daya saing serta memperluas jangkauan pemasaran atau penjualan adalah teknologi internet.

Internet saat ini telah berkembang dengan pesat. Melihat kelebihan-kelebihan dari internet, banyak perusahaan memanfaatkan untuk kepentingan bisnis yang berbeda-beda. Pesatnya pertumbuhan internet ini tidak lepas dari keikutsertaan dan dukungan dunia bisnis. Dunia bisnis melihat internet sebagai pasar global yang sangat besar dengan akses 24 jam sehari, sehingga dapat dimanfaatkan sebagai media untuk melakukan promosi, menyediakan informasi untuk pelanggan, bahkan melakukan transaksi bisnis tanpa dibatasi geografis maupun perbedaan waktu. Kegiatan perdagangan melalui media internet ini disebut sebagai e-commerce atau perdagangan elektronik. Dengan adanya e-commerce dapat mengubah kebiasaan pelanggan yang memesan dan membeli secara konvensional menjadi secara online. Pemenuhan kebutuhan konsumen pun berubah, perusahaan harus mampu menyediakan layanan yang mudah diakses, mudah digunakan, dan sederhana tetapi tetap dapat menjadi media pemasaran sekaligus membantu pelanggan dalam melakukan transaksi. Melalui media elektronik dan penggunaan internet, hambatan-hambatan konvensional yang menghalangi pelanggan melakukan transaksi dapat diatasi. Selain itu perusahaan juga dapat berinteraksi langsung dengan perusahaan lain ataupun dengan pelanggan. Bahkan saat ini dapat dipastikan hadirnya teknologi $e$ commerce membuat kalangan bisnis berlomba-lomba untuk mengeksistensikan perusahaannya di dunia internet.

PT. Sangaji Musik Graha (PT. SMG) adalah perusahaan yang bergerak di bidang musik. Perusahaan ini menjual berbagai macam $C D$ (Compact Disc) musik dari berbagai jenis genre lagu. Selain CD, PT. SMG juga menjual musik dan film dalam bentuk VCD (Video Compact Disc) dan DVD (Digital Video Disc). Pemasaran dan penjualan yang dilakukan oleh PT. SMG selama ini bersifat tradisional yaitu, pembeli datang langsung ke gerai untuk melihat produk terbaru atau untuk membeli. Mengingat sistem penjualan yang dilakukan selama ini sangat terbatas maka secara tidak langsung PT. SMG dituntut untuk mampu bersaing dalam merebut konsumen sebanyak mungkin seiring dengan semakin banyaknya perusahaan-perusahaan musik sejenis yang telah memanfaatkan e-commerce untuk memperluas jangkauan pemasaran dan penjualan.

\section{METODE}

Metode Perancangan terbagi ke dalam perancangan model bisnis yang terdiri dari: nilai proposisi, penawaran online, sumberdaya sistem dan model pendapatan. Sedangan perancangan antarmuka pelanggan menggunakan konsep 7C framework yang terdiri dari: context (konteks), content (konten), community (komunitas), customization (penyesuaian), connection (koneksi), commerce (perdagangan).

\section{Tinjauan Pustaka}

\section{Electronic Business (e-business)}


Menurut O’Brien dan Marakas (2006, p.214), “E-business merupakan penggunaan dari internet dan jaringan lain serta teknologi informasi untuk mendukung e-commerce, komunikasi perusahaan dan proses bisnis web, dimana keduanya berada dalam jaringan perusahaan dan dengan pelanggan dan rekan bisnis. E-business meliputi e-commerce, yang mana melibatkan pembelianpenjualan dan pemasaran, serta servis produk, dan servis informasi pada internet dan jaringan.”

\section{E-commerce}

Menurut Turban et al. (2002, p.3), "E-commerce adalah kegiatan untuk membeli, menjual, atau menukarkan barang-barang, jasa dan informasi melalui jaringan komputer, termasuk internet.”

\section{Business Model}

Rayport and Jaworski (2003, p.112) menyatakan bahwa model bisnis terdiri dari 4 komponen (Gambar 1), yaitu:

(1) Nilai proposisi (value proposition), yang merupakan pemilihan segmen pasar yang dituju oleh perusahaan berdasarkan sumber daya yang dimiliki perusahaan dan keuntungan yang diperoleh oleh segmen tersebut.

(2) Penawaran online (online offering), yang merupakan penawaran yang dilakukan perusahaan secara online berdasarkan customer decision process.

(3) Sumberdaya sistem (resource sistem), yang mengidentifikasi sumber daya yang dimiliki perusahaan dan core benefit / keuntungan apa yang diperoleh dari sumber daya tersebut.

(4) Model pendapatan (revenue model) atau cara-cara yang digunakan oleh perusahaan untuk mendapatkan pendapatan usahanya.

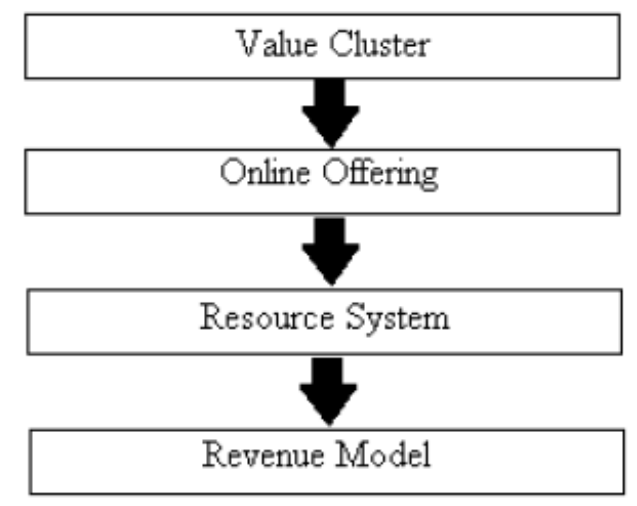

Gambar 1. Komponen bisnis model.

(Sumber: Rayport dan Jaworski, 2003, p.111)

\section{Antarmuka Pelanggan}

Menurut Rayport dan Jaworski (2003, p.151), terdapat 7 elemen (7C) dalam mendesain/merancang antarmuka pelanggan, yaitu konteks (context), konten (content), komunitas (community), penyesuaian (customization), komunikasi (communication), koneksi (connection), dan perdagangan (commerce). Masing-masing dari 7 elemen tersebut harus disesuaikan satu sama lain supaya memenuhi model bisnis. Berikut ini adalah penjabaran dari masing-masing elemen tersebut:

(1) Konteks dari suatu rancangan terbagi menjadi dua dimensi yaitu estetika yang menonjolkan sifat artistik suatu situs, dan fungsi yang berhubungan dengan kegunaan dari website; 
(2) Konten/isi dari suatu situs bisa berupa dominasi produk dimana tujuan dari website adalah menjual produk, dominasi informasi yang tujuannya menyediakan informasi, dan dominasi layanan yang bertujuan memberi bantuan pada user untuk melakukan sesuatu;

(3) Komunitas merupakan interaksi antara pemakai site, dapat terjadi melalui interaksi one-to-one atau di antara banyak pemakai;

(4) Penyesuaian adalah suatu kemampuan website untuk menyesuaikan dirinya;

(5) Komunikasi mengacu pada dialog antara suatu website dan para pemakainya. Hal ini dapat berupa tiga format: komunikasi site-to user, komunikasi user-to site, komunikasi dua arah;

(6) Koneksi mengacu pada tingkatan dimana suatu website dihubungkan dengan halaman website lain;

(7) Perdagangan, bagaimana suatu web mampu melakukan perdagangan dengan menjual barangbarang, produk, dan jasa.

\section{HASIL DAN PEMBAHASAN}

\section{Model Bisnis}

\section{Nilai Proposisi}

Dalam membangun nilai proposisi, ada tiga hal yang perlu diperhatikan. Pertama, target segmen (target segment). Segmen pelanggan PT. SMG terbagi atas usia (anak-anak dan dewasa), jenis kelamin (pria dan wanita), kategori produk (CD, VCD, DVD), serta aliran music (pop, rock, jazz, hip-hop, dan dangdut) atau film (kartun, laga, drama, dan komedi). Berdasarkan pembagian segmen di atas, target segmen dari PT. SMG adalah pria dan wanita dewasa yang menyukai musik (jazz, pop, rock, hip-hop). Kedua, pemilihan keuntungan (benefit choice). Dengan model bisnis online, PT. SMG dapat menawarkan berbagai keuntungan kepada pelanggannya, yaitu: informasi mengenai produk terkini dan lengkap, transaksi dapat dilakukan melalui jaringan internet, pelanggan dapat mengakses informasi yang dibutuhkan $24 \times 7$, kemudahan melakukan transaksi, dan produk yang kualitasnya sudah terjamin. Ketiga, pemilihan sumber daya (resource choice), seperti pemasok yang ternama dan terjamin kualitas produknya, latar belakang perusahaan yang sudah dikenal oleh masyarakat (memiliki gerai-gerai yang tersebar pada pusat perbelanjaan ternama di Jakarta), website yang dapat diakses oleh pelanggan dimana saja dan kapan saja, karyawan yang berpengalaman sehingga dapat melayani kebutuhan pelanggan dengan lebih baik.

\section{Penawaran Online}

Setelah menentukan nilai proposisi, langkah selanjutnya adalah menentukan cakupan produk, jasa atau informasi yang ditawarkan PT. SMG dalam model bisnis online, yang terdiri dari beberapa tahap.

Pertama, mengindentifikasi ruang lingkup dari penawaran. Ada dua macam ruang lingkup penawaran, yaitu yaitu category-specific dominance dan cross-category dominance. PT. SMG termasuk cross-category dominance karena produk yang dijual lebih dari satu kategori produk. Cakupan produk yang ditawarkan PT. SMG meliputi $C D$, VCD, dan DVD.

Kedua, mengidentifikasi proses pengambilan keputusan dari pelanggan. Proses pengambilan keputusan oleh pelanggan terdiri dari tahap pre-purchase, purchase, dan post-purchase. Pada tahap pre-purchase, pelanggan melewati beberapa langkah lagi, yaitu mengenali masalah dan kebutuhan, mencari informasi tentang kebutuhannya dan mengevaluasi alternatif pilihan-pilihan yang ada. Pelanggan yang ingin membeli produk akan mencari situs-situs yang menjual produk yang sama. 
Setelah itu membandingkan atau mengevaluasi harga, kualitas dan parameter lainnya dari situs-situs yang ditemukannya. Tahap purchase merupakan tahap dimana pelanggan memutuskan untuk membeli dan melewati proses pembelian. Apabila pelanggan memutuskan untuk melakukan pembelian, maka pelanggan akan disediakan "Keranjang Belanja" untuk menampung produk yang dibelinya dan kemudian melakukan transaksi pembelian. Tahap post-purchase tahap ini adalah dimana akan dilakukan evaluasi tingkat kepuasan pelanggan setelah melakukan pembelian di PT. SMG. Perusahaan menyediakan menu "Saran" yang dapat digunakan oleh pelanggan apabila ingin memberi masukan mengenai PT. SMG maupun produk-produk yang dijual.

Ketiga, memetakan produk dan layanan ke dalam proses pengambilan keputusan pelanggan. Dalam mengambil keputusan untuk melakukan pembelian ada beberapa tahapan-tahapan yang disertai penawaran produk secara online, yaitu: need recognition 'pengenalan kebutuhan'- beberapa alasan pelanggan membeli $C D, V C D, D V D$ adalah untuk dijadikan sebagai koleksi atau sebagai hadiah; ide dan informasi - untuk membantu pelanggan memperoleh informasi, PT. SMG menyediakan beberapa menu dan fitur diantaranya adalah menu produk-produk terbaru, menu tentang kami, menu lokasi, menu saran, menu cara pembelian, menu promosi-promosi serta fitur pencarian; evaluasi - setelah memperoleh informasi, selanjutnya pelanggan akan melakukan evaluasi produk di antaranya mengenai harga, artis dan format dari produk tersebut; keputusan pembelian - setelah melakukan evaluasi, pelanggan dapat memutuskan untuk melakukan transaksi pembelian secara online melalui keranjang belanja dan transaksi e-commerce; pasca pembelian - setelah bertransaksi, pelanggan dapat melakukan pembayaran via transfer. Kemudian, pelanggan melakukan konfirmasi pembayaran. Setelah berhasil, barang akan segera dikirim.

\section{Sumber Daya Sistem}

Sumber daya yang perlu untuk mendukung sistem e-commerce PT. SMG adalah sebagai berikut: supplier yang berkualitas dan terjamin; latar belakang perusahaan yang sudah dikenal oleh masyarakat (brand yang kuat) sehingga menimbulkan kenyamanan dan keamanan dalam melakukan transaksi; website yang dapat diakses oleh pelanggan dimana saja dan kapan saja; karyawan yang berpengalaman sehingga dapat melayani kebutuhan pelanggan dengan lebih baik.

\section{Model Pendapatan}

Dalam penerapan sistem e-commerce ini diperlukan biaya-biaya operasional untuk menjalankannya. Sumber biaya ini dapat diperoleh dari pendapatan yang dapat dihasilkan oleh sistem e-commerce ini. Satu model pendapatan yang dapat diperoleh dari sistem e-commerce yaitu produk, dimana pada model pendapatan ini sistem e-commerce yang berbasiskan website memperoleh pendapatan dari laba penjualan produk. Model pendapatan ini adalah pendapatan utama sistem $e$ commerce pada PT. SMG.

\section{Model Bisnis Online}

Untuk dapat menentukan model bisnis yang harus digunakan oleh PT. SMG, ada beberapa faktor yang harus dianalisis. Pertama, manfaat Pokok (Core Benefits) dan nilai proposisi. Target segmen dari PT. SMG adalah pria dan wanita dewasa yang menyukai musik (jazz, pop, rock, hip-hop). PT. SMG juga menyediakan berbagai produk yang bervariasi dan orisinil serta selalu up-to-date dengan pilihan yang lengkap dan harga kompetitif serta akses yang mudah, yang didukung oleh saluran distribusi luas, pengaturan pengiriman oleh TIKI dan jaringan supplier. Selain itu PT. SMG juga didukung dengan berbagai rekanan yakni Univesal, Sony BMG, EMI, Warner, Harika, dan Nav yang selalu bertukar informasi dan produk sehingga produk-produk di PT. SMG dapat dipastikan selalu up-to-date. Dimana keseluruhan manfaat pokok tersebut bisa berjalan dengan baik dengan adanya dukungan teknologi yang semakin berkembang. 
Kedua, penawaran online (online offering). PT. SMG berkonsentrasi pada pangsa pasar B2C (business to consumers). Dan hal yang ditawarkan secara online adalah produk dan informasi mengenai musik dan film.

Ketiga, sumber daya kunci (key resource). PT. SMG didukung oleh komunikasi pasar, pengaturan jasa pengiriman ke pelanggan melalui TIKI, dan jaringan supplier.

Keempat, model pendapatan (revenue model). Pendapatan diperoleh dari hasil penjualan produk yang terdapat dalam website, ini merupakan sumber pendapatan utama PT. SMG dalam sistem penjualan berbasis website tersebut. Kesetiaan pelanggan juga merupakan faktor kunci dalam pendapatan, karena pelanggan yang setia akan membeli kembali, yang kemudian secara otomatis akan meningkatkan penjualan. Setelah menganalisis manfaat pokok dan nilai proposisi, penawaran online, sumberdaya kunci, serta model pendapatan maka dapat diketahui model bisnis PT. SMG adalah widest-assortment model, yaitu model bisnis online yang bersaing pada berbagai jenis kategori produk.

\section{Antar Muka Pelanggan}

Dalam merancang website PT. SMG, digunakan 7 elemen desain dari antarmuka pelanggan (Gambar 2 dan 3). Elemen pertama adalah konteks (context). Website PT. SMG akan dirancang dengan konsep integrasi konteks, dimana website ini baik dari sisi estetika maupun sisi fungsional, sama-sama seimbang. Jadi, selain memfokuskan pada fungsi-fungsi yang ada, tampilan website ini pun dibuat semenarik mungkin agar dapat menarik perhatian dari pelanggan. Fungsi-fungsi yang ada dalam website disediakan untuk membantu para pelanggan dalam mengakses website PT. SMG dan informasi di dalamnya.

Untuk fungsional, berikut ini adalah beberapa komponen penting di dalam fungsi. Komponen fungsional pertama adalah pembagian seksi (section breakdown). Menu-menu terdapat pada bagian atas, samping kanan, dan samping kiri layar monitor setiap halaman web. Menu pada bagian atas terdiri dari Beranda (Halaman Utama), Tentang Kami, Lokasi (lokasi store dan nomor telepon), Saran (saran dari pelanggan, dan Cara Pembelian (penjelasan mengenai cara pembelian produk). Menu pada bagian kanan ini terdiri dari menu Registrasi, Login, Dan Promosi. Bila sudah login, akan ada menu tambahan, yaitu: Ubah Data, Ubah Kata Sandi, Keranjang Belanja (daftar produk yang akan kita beli), Histori Pembelian (daftar produk yang telah kita beli pada transaksi sebelumnya), Konfirmasi Pembayaran (keterangan bila pelanggan sudah melakukan pembayaran), dan Logout. Menu pada bagian kiri terdiri dari menu Pencarian (berisi pencarian produk berdasarkan kategori-kategorinya), Kategori Musik (Pop, Rock, Jazz, Audiophile, Hip Hop, Dangdut, dan Rohani), dan Kategori Film (Action, Animasi, Komedi, Drama, Horor). Komponen fungsional kedua adalah struktur penghubung (linking structure) - berupa fitur-fitur yang memudahkan pelanggan bergerak dari satu halaman ke halaman lain dengan mudah untuk mencari produk yang diinginkan pelanggan tersebut. Komponen fungsional ketiga adalah alat navigasi (navigation tools). Terdapat menu pencarian yang dapat membantu pelanggan mencari produk yang diinginkan berdasarkan kategori produk (musik atau film), judul atau artis, dan format (CD/VCD/DVD). Komponen fungsional keempat adalah kecepatan. Dengan menggunakan ukuran gambar tidak terlalu besar dan animasi flash ukuran kecil, diharapkan dapat mempersingkat waktu loading website. Komponen fungsional kelima adalah keandalan (reliability). Untuk menjaga performa website serta untuk menghindari kemungkinan error, pihak PT. SMG dapat terus memantau dengan melakukan maintenance secara rutin. Komponen fungsional keenam adalah kebebasan platform (platform independence). Website PT. SMG dapat diakses oleh hampir semua browser, seperti Internet Explorer , Mozilla Firefox, Opera, Google Chrome, dan lainlain. Komponen fungsional ketujuh adalah akses media (Media Accessibility). Website ini dibangun menggunakan teknologi PHP Hypertext Protocol, mengkombinasikan CSS (Cascading Style Sheet), HTML (Hyper Text Mark-Up Language), dan Javascript. Untuk penyimpanan data digunakan MySQL. 
Untuk estetika, komponen pentingnya terdiri dari: skema warna (color scheme) menggunakan warna dasar putih dan konsisten pada setiap halaman yang dimaksudkan supaya pelanggan merasa nyaman dalam mengunjungi website PT. SMG; tema visual (visual themes) - dibuat dengan nuansa sederhana tapi tetap menonjolkan baik sisi fungsional maupun estetikanya agar para pelanggan bisa mendapatkan informasi mengenai produk dan visualisasi dari produk itu sendiri. Alasan lain juga supaya para pelanggan website tidak membutuhkan waktu lama dalam mengaksesnya. Website ini terdiri dari logo, pilihan textbox untuk menu pencarian, pilihan menu untuk login, pilihan produk berdasarkan kategori. Juga terdapat pilihan Beranda, Tentang Kami, Lokasi, Saran, Cara Pembelian, Keranjang Belanja, Histori Pembelian, dan Konfirmasi Pembayaran.

Elemen desain antarmuka kedua adalah konten (Content). Isi dari website merupakan gabungan antara teks dan gambar yang sudah mewakili apa yang ingin diinformasikan kepada pelanggan. Konten terdiri dari: bauran penawaran (offering mix) - gambar produk-produk musik dan film serta keterangan informasi yang berkaitan dengan produk-produk yang dijual. Hal ini bertujuan untuk menjual barang kepada pelanggan dan untuk mendukung keputusan pelanggan dalam membeli produk PT. SMG. Dalam hal ini PT. SMG termasuk product-dominant; bauran daya pemikat (appeal mix) - promosi-promosi yang diberikan kepada pelanggan. Pada halaman beranda website dapat terlihat promosi apa saja yang ditawarkan kepada pelanggan secara up-to-date; bauran multimedia (multimedia mix) - kombinasi teks, gambar, audio, video. Dalam website ini terlihat gambar-gambar mengenai produk-produk yang dijual yang dikombinasikan dengan teks sebagai keterangan informasi dari produk tersebut; bauran aktualitas (timeliness mix) - untuk melihat isi website dari segi informasi yang harus diperbaharui, seperti harga produk, promosi, dan produk terbaru.

Elemen ketiga adalah komunitas (community). Website ini dikategorikan dalam nonexistent, dimana tidak ada komunitas yang menawarkan kepada pelanggan untuk berinteraksi satu dengan lainnya. Hal ini dilakukan karena pertimbangan awal bagi yang mengakses website ini hanya untuk mencari informasi dan melakukan pembelian atas produk yang dijual. Elemen keempat adalah penyesuaian (customization). Website ini tidak menyediakan penyesuaian yang khusus bagi setiap pelanggannya, dimana setiap pelanggan diperlakukan sama, dalam arti kata mendapat tampilan yang sama pada website, yang membedakan hanya ketika sudah menjadi anggota, pelanggan dapat melakukan transaksi pembelian. Elemen kelima adalah komunikasi (Communication). Klasifikasi komunikasi pada website PT. SMG adalah one-to-one, nonresponding user, yaitu melalui menu "Saran" yang ada di dalam website.

Elemen keenam adalah koneksi (connection). Koneksi dari website PT.SMG adalah minimum karena sifatnya sebagai destination site. Jadi pelanggan yang berada pada website PT. SMG adalah pelanggan yg benar-benar sedang mencari atau melihat-lihat dan hendak melakukan transaksi untuk produk PT. SMG. Dengan kata lain website ini berfungsi sebagai platform transaksional sehingga situs tersebut menjadi destination site atau tempat tujuan akhir. Elemen ketujuh sekaligus terakhir adalah perdagangan (commerce). Perdagangan yang terdapat pada website hanya dapat dilakukan oleh pelanggan yang sudah teregistrasi pada website. Pelanggan yang belum mendaftar tidak dapat melakukan perdagangan atau transaksi, tetapi hanya dapat mencari informasi produk yang dijual dan informasi perusahaan, sehingga perdagangan pada PT. SMG tidak terlalu rumit. Fungsi perdagangan sendiri dimungkinkan oleh: registrasi - untuk dapat melakukan transaksi e-commerce melalui website PT. SMG, pelanggan terlebih dahulu harus melakukan registrasi dengan mengisi form registrasi yang ada di dalam website. Ini dilakukan agar data pelanggan tersimpan dalam database, sehingga pelanggan dapat membeli dan melakukan transaksi berulang-ulang tanpa harus dimintai datanya terusmenerus. Hal ini dimaksudkan untuk memudahkan pelanggannya jika akan melakukan transaksi yang berikutnya. Jika belum login, pelanggan hanya bisa melihat-lihat produk tersebut saja dan tidak dapat melakukan transaksi; keranjang belanja - pelanggan dapat meng-klik tombol "tambah ke keranjang" pada produk yang ingin dibeli dan secara otomatis produk yang kita pilih akan menambah di "Keranjang Belanja”. Di halaman "Keranjang Belanja", pelanggan dapat membantalkan dan 
menambah produk yang ingin dibeli. Setelah selesai, pelanggan dapat mengklik "konfirmasi pesanan" untuk melakukan transaksi. Pelanggan dapat melakukan pembayaran via transfer.

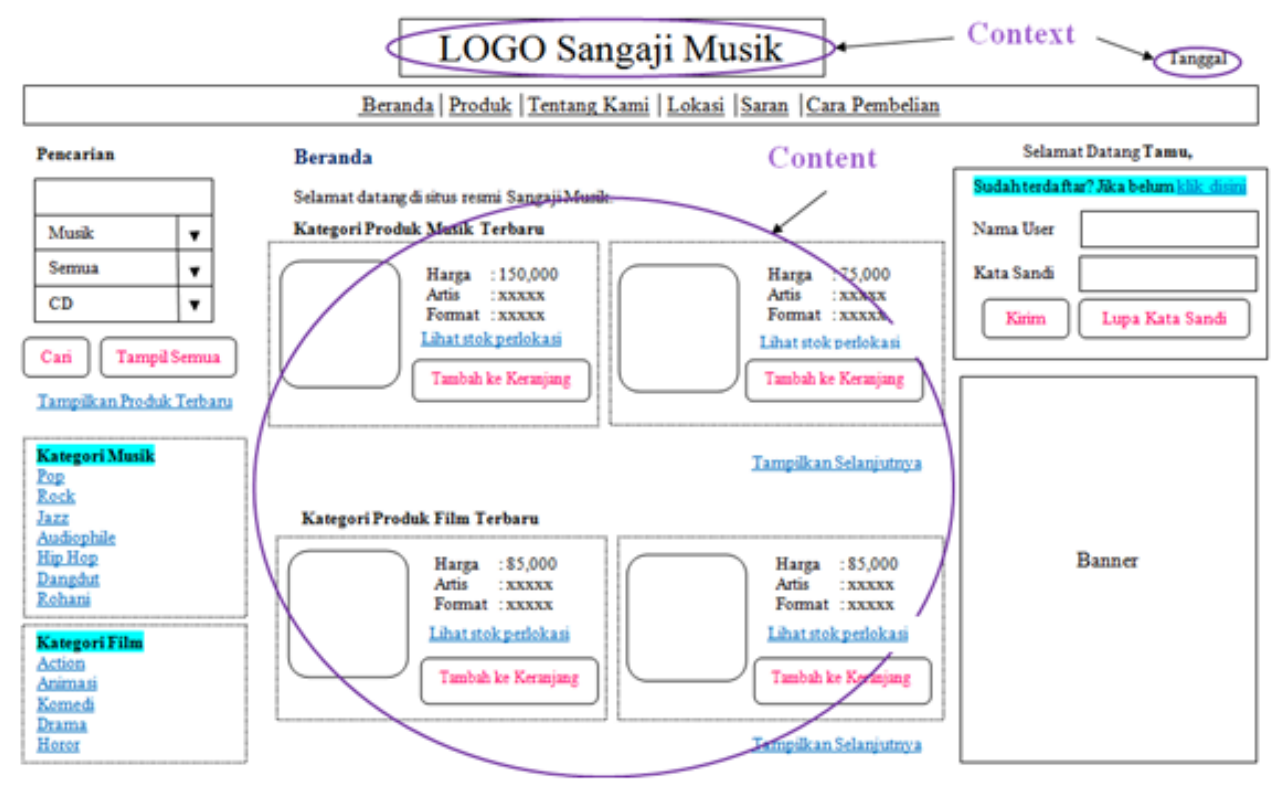

Gambar 2. Rancangan layar halaman "Beranda”.

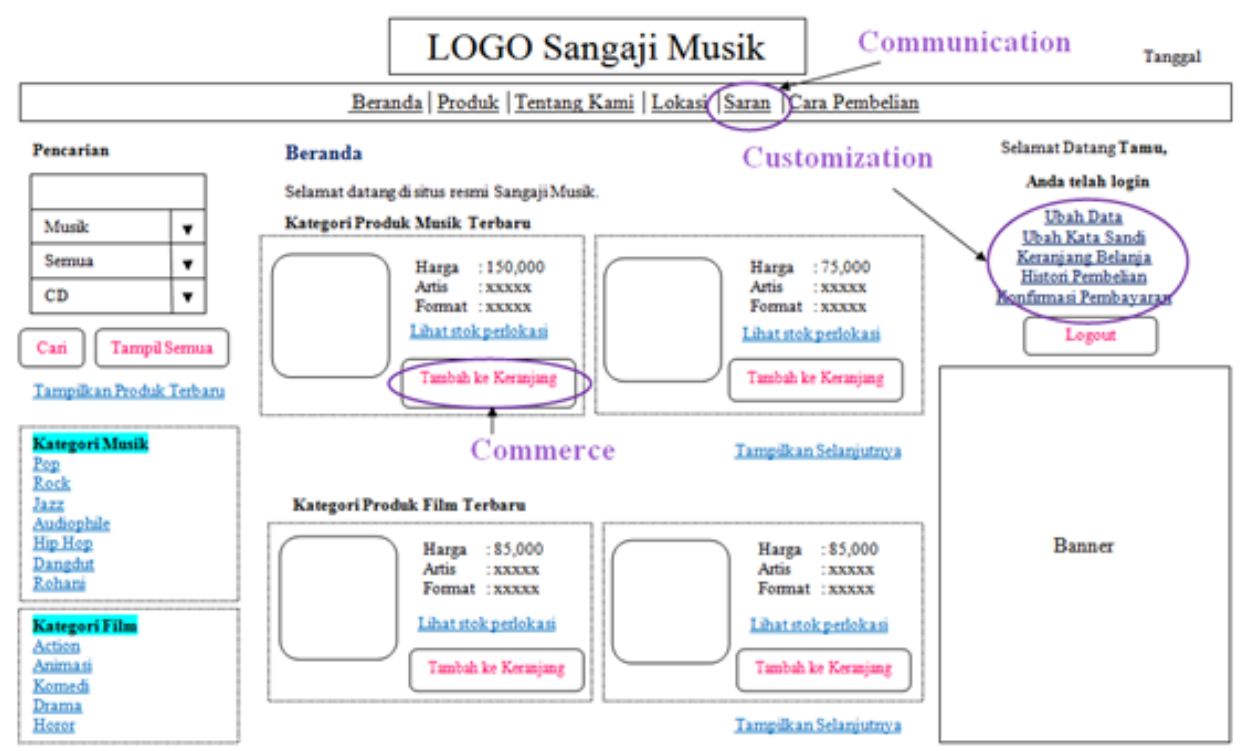

Gambar 3. Rancangan layar halaman anggota (setelah login).

\section{Tampilan Layar Aplikasi E-commerce}

Gambar 4 dan 5 di bawah ini menampilkan layar aplikasi e-commerce pada PT. SMG, dimana pada halaman ini menampikan produk yang ditawarkan pada bagian tengah website, pada bagian kanan website menampilkan menu-menu untuk berpindah ke halaman lainnya dengan cepat. Pada 
bagian kiri terdapat menu-menu bagi anggota yang telah melakukan login. Pada bagian ini anggota dapat melakukan perubahan data (ubah data), perubahan kata sandi (ubah password), melihat barangbarang yang telah dipilih untuk dibeli (keranjang belanja), melihat transaksi-transaksi pembelian sebelumnya (histori pembelian) dan melakukan konfirmasi status pembayaran yang telah dilakukan (konfirmasi pembayaran).

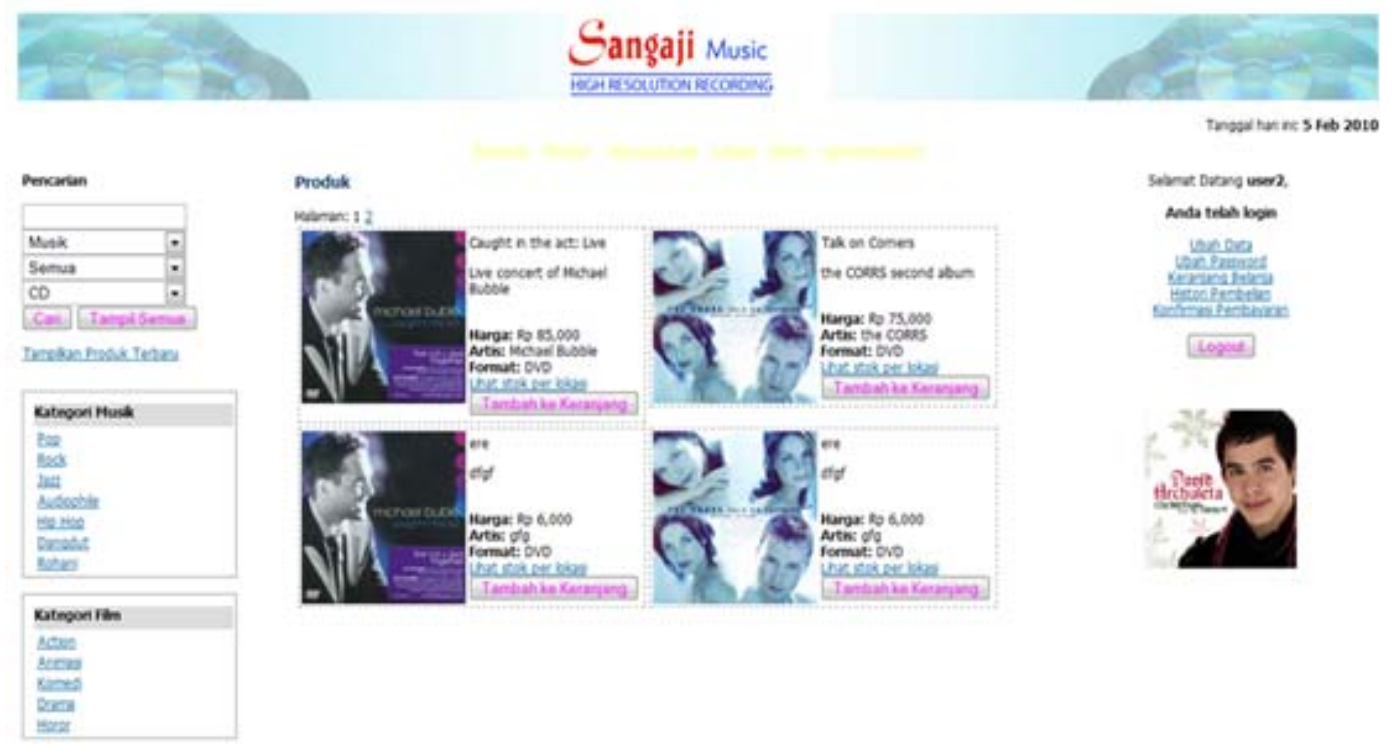

Gambar 4. layar halaman setelah pelanggan melakukan login.

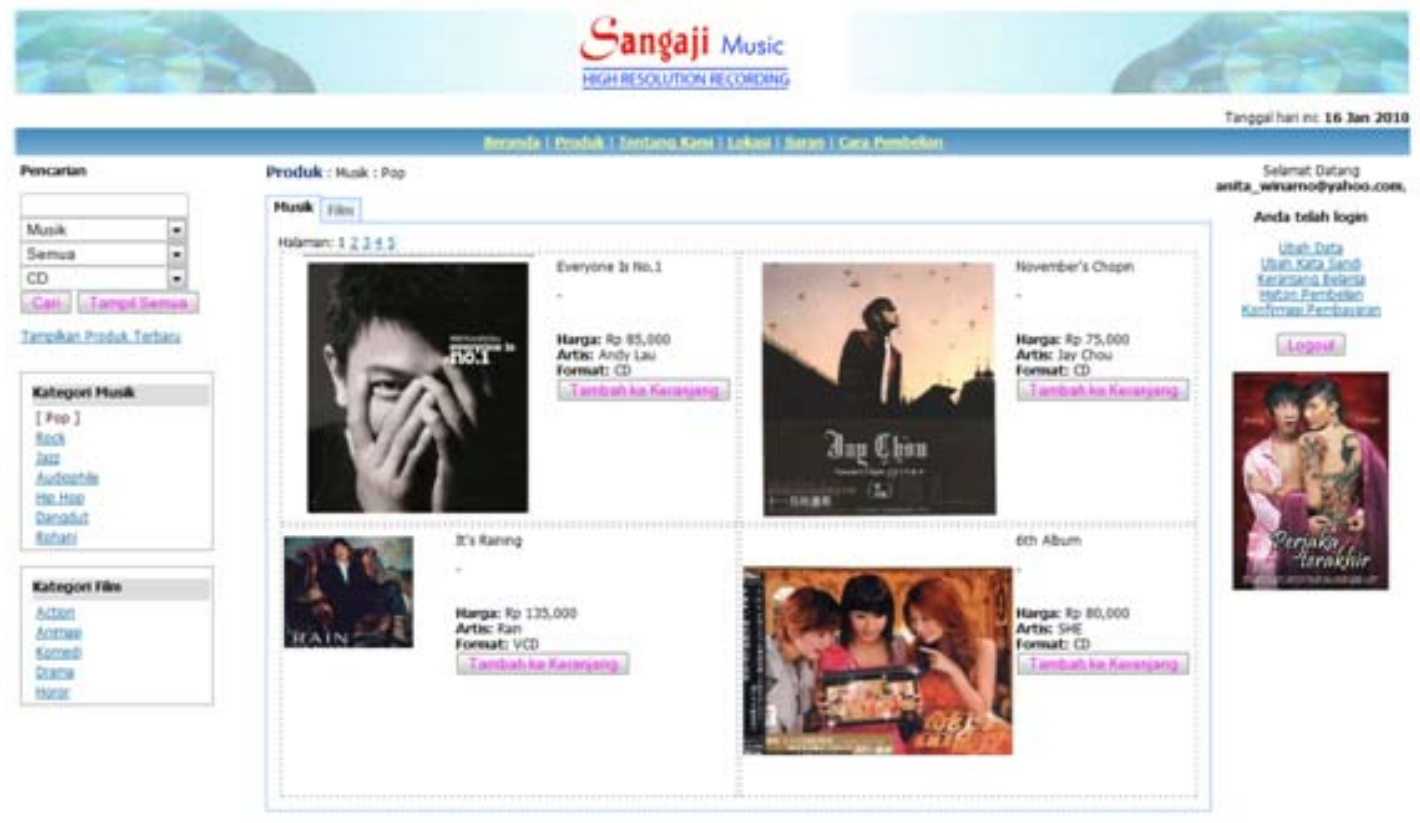

Gambar 5. Layar halaman "Produk". 


\section{PENUTUP}

Target segmen dari PT. SMG adalah pria dan wanita dewasa yang menyukai musik (jazz, pop, rock, hip-hop). Setelah menganalisis manfaat pokok dan nilai proposisi, penawaran online, sumber daya kunci, serta model pendapatan, dapat diketahui model bisnis PT. SMG adalah widest-assortment model, yaitu model bisnis online yang bersaing pada berbagai jenis kategori produk. Content dari antarmuka website PT. SMG tergolong product-dominant karena PT. SMG menawarkan berbagai produk musik dan film.

\section{DAFTAR PUSTAKA}

O’Brien, J. A. \& Marakas, G. M. (2006). Management Information System. New York: McGraw-Hill.

Rayport, J. F. \& Jaworski, B. J. (2003). Introduction to E-Commerce (2nd ed.). Singapore: McGrawHill.

Turban, E., King, D., Lee, J., Warkentin, M., Michael, H. C. (2002). Electronic Commerce 2002: A Managerial Perspective (international edition). New Jersey: Pearson Prentice Hall. 